\title{
Improved biological activity of a mutant endostatin containing a single amino-acid substitution
}

\author{
Y Yokoyama' and S Ramakrishnan ${ }^{*, 1,2,3}$ \\ 'Department of Pharmacology, University of Minnesota, 6-I 20 Jackson Hall, 32 I Church Street, S.E., Minneapolis, MN 55454, USA; ${ }^{2}$ Obstetrics and \\ Gynecology, University of Minnesota, Minneapolis, MN, USA; ${ }^{3}$ Comprehensive Cancer Center, University of Minnesota, Minneapolis, MN, USA
}

\begin{abstract}
Human endostatin has an internal Asn-Gly-Arg (NGR) motif at position 126-128 following a proline at position 125. Asn-Gly-Argcontaining peptides have been shown to target tumour vasculature and inhibit aminopeptidase $\mathrm{N}$ activity. We previously compared the in vitro and in vivo biological activities of native endostatin and endostatin with a proline to alanine mutation (PI25A-endostatin). PI25A-endostatin exhibited greater inhibition of both endothelial cell proliferation and human ovarian cancer growth compared to native endostatin. Here we explore further the effects on biological activity of the PI25A mutation, and show that aminopeptidase $\mathrm{N}$ is not involved. To determine whether the increased biological activity of the mutant was due to unmasking of downstream NGRsequence, effect of endostatin on aminopeptidase $\mathrm{N}$ activity was investigated. Neither the native nor the PI25A-endostatin inhibited aminopeptidase N. However, synthetic peptides consisting of the SI I 8-T I 3 I region of endostatin inhibited aminopeptidase N. These results suggest that the internal NGR site in native or mutant endostatin is not accessible to aminopeptidase $\mathrm{N}$, and that this activity is not involved in the enhanced biological activity of the PI25A form. PI25A-endostatin bound to endothelial cells more efficiently than native endostatin and exhibited greater inhibition of not only proliferation but also migration of endothelial cells. PI25A-endostatin also localised into tumour tissue to a higher degree than the native protein, and displayed greater inhibition of growth of colon cancer in athymic mice. Both proteins inhibited tumour cell-induced angiogenesis effectively. Real-time PCR analysis showed that both native and PI25A-endostatin decreased expression of key proangiogenic growth factors. Vascular endothelial growth factor and angiopoietin I were downregulated more by the mutant. These studies suggest that the region around PI25 can be modified to improve the biological activity of endostatin.

British Journal of Cancer (2004) 90, 1627-1635. doi:I0.1038/sj.bjc.6601745 www.bjcancer.com
\end{abstract}

Published online 30 March 2004

(c) 2004 Cancer Research UK

Keywords: endostatin; point mutation; tumour angiogenesis; ovarian cancer; colon cancer

Endostatin is a proteolytic fragment of the noncollagenous domain of collagen type XVIII (O'Reilly et al, 1997), a component of the basement membrane. Endostatin inhibits growth factor-induced proliferation and migration of endothelial cells in vitro and angiogenesis in vivo. A number of independent studies have shown that endostatin treatment inhibits tumour growth by blocking angiogenesis (Boehm et al, 1997; O'Reilly et al, 1997; Dhanabal et al, 1999). Endostatin binds to at least two distinctive sets of molecules on the endothelial cell surface, $\alpha_{5} \beta_{1} / \alpha_{\mathrm{v}} \beta_{3}$ integrin (Rehn et al, 2001; Wickstrom et al, 2002) and glycosyl-phosphatidylinositol (GPI) anchored heparin sulphate proteoglycan (HSPG), or glypican (Karumanchi et al, 2001). Glypican is believed to sequester endostatin and present it to the integrins, thereby forming a receptor-signalling complex. Binding to integrins is linked to phosphorylation of SH2 containing Shb adaptor protein, which is implicated in the apoptotic cascade (Dixelius et al, 2000). Such interactions can activate intracellular signalling leading to inhibition of endothelial cell proliferation and migration (Rehn et al, 2001; Shichiri and Hirata, 2001). A recent study showed that

*Correspondence: Dr S Ramakrishan; E-mail: sunda00I@umn.edu Received 9 September 2003; revised 26 January 2004; accepted 29 January 2004; published online 30 March 2004 wnt-signalling pathways might also be modulated by endostatin (Hanai et al, 2002). In addition to these direct actions, endostatin has been shown to bind and inactivate metalloproteinases in vitro (Kim et al, 2000). These studies collectively imply that the mechanism of endostatin action is diverse and complex. Understanding the structure/function of endostatin therefore will help in improving its efficacy to inhibit tumour growth.

Human endostatin containing a point mutation at position 125 has been identified during expression cloning (Yokoyama and Ramakrishnan, 2002). Proline 125 is followed by a tripeptide, AsnGly-Arg (NGR), a sequence that is known to target endothelial cells (Pasqualini et al, 2000). In fact, chemical linkage of doxorubicin to NGR peptides inhibited tumour growth efficiently (Arap et al, 1998). Asn-Gly-Arg sequence has also been shown to bind and inhibit aminopeptidase $\mathrm{N}$ localised on vascular endothelial cells of tumours. The P125A-mutation is not a conservative change and would be expected to alter peptide folding around the mutation site. However, we were able to express P125A-endostatin in yeast in fully soluble form, and showed that it has similar gross secondary structures as native endostatin. P125A-endostatin inhibited in vitro endothelial cell proliferation and in vivo growth of ovarian cancer more effectively when compared to native endostatin (Calvo et al, 2002). 
In this study, we have further explored the differences between native and P125A-endostatin. We report that the mutant protein binds more effectively to endothelial cells and is more effective in inhibiting not only endothelial cell proliferation but also migration in vitro. P125A-endostatin also displayed improved inhibition of colon cancer growth in athymic mice, and greater downregulation of human vascular endothelial growth factor (VEGF) and human angiopoietin 1 (Ang1) from tumours. Neither native nor mutant endostatin inhibited aminopeptidase $\mathrm{N}$ activity. These studies suggest that structural changes in endostatin can be used to improve the biological activity of human endostatin.

\section{MATERIALS AND METHODS}

\section{Cell lines and culture conditions}

Bovine adrenal gland capillary endothelial (BCE) cells were obtained from Clonetics Inc. (San Diego, CA, USA). Culture conditions of human umbilical vein endothelial cells (HUVEC) have been published previously (Ramakrishnan et al, 1996). Human colon carcinoma cell line, LS174T, was obtained from American Type Culture Collection (ATCC, Rockville, MD, USA). LS174T cells were cultured in RPMI-1640 (GIBCO BRL, Gaithersburg, MD, USA) supplemented with $10 \% \mathrm{FBS}, 100 \mathrm{U} \mathrm{ml}^{-1}$ penicillin, $100 \mu \mathrm{g} \mathrm{ml}^{-1}$ streptomycin and $2 \mathrm{~mm}$ L-glutamine.

\section{Cloning, expression and purification of mutant human endostatin}

The following primers were used to amplify the C-terminal end of collagen type XVIII (183 amino acid residues) by RT - PCR:

\section{Up: GGGGAATTCCACAGCCACCGCGACTTCCAG, Down: GGGGCGGCCGCCTACTTGGAGGCAGTCATGAAGCT.}

The PCR product was cloned into pPICZ- $\alpha \mathrm{A}$ vector (Invitrogen, Carlsbad, CA, USA) and sequenced. Selected clones were electroporated into X-33 host strain of Pichia pastoris (Invitrogen). Previously published methods were followed for expression and purification of endostatin (Yokoyama et al, 2000).

\section{Structural analysis by circular dichroism}

Circular dichroism (CD) studies of endostatin and P125Aendostatin were carried out in a JASCO J-710 spectropolarimeter. Protein samples were prepared in PBS at a concentration of $100 \mu \mathrm{g} \mathrm{ml}^{-1}$. Path length of the cell was $0.1 \mathrm{~cm}$. Circular dichroism spectra and molar ellipticity were obtained over the wavelength range of $195-260 \mathrm{~nm}$.

\section{Cell attachment assay}

The method of cell attachment assay described previously was used (Maeshima et al, 2000). A measure of 1 nmole well $^{-1}$ of endostatin preparations or $0.2 \%$ gelatin were used to coat 96 -well plates. Human umbilical vein endothelial cells were prelabelled with a vital, fluorescence dye, $5 \mu \mathrm{M}$ 5-(and-6)-carboxyfluorescein diacetate, succinimidyl ester (5(6)-CFDA) (Molecular Probes, Eugene, OR, USA) for $10 \mathrm{~min}$ at $37^{\circ} \mathrm{C}$. Cells were added to wells at a density of 40000 cells well $^{-1}$. After $1 \mathrm{~h}$ incubation at $37^{\circ} \mathrm{C}$, unbound cells were removed, and fraction of bound cells was determined by a fluorescence plate reader (Cyto Fluor II; PerSeptive Biosystems, Framigham, MA, USA) (excitation, $485 \mathrm{~nm}$, emission, $530 \mathrm{~nm}$ ).

\section{Aminopeptidase $\mathrm{N}$ activity}

Aminopeptidase $\mathrm{N}$ activity was determined by the method described previously (Arap et al, 1998). Human umbilical vein endothelial cell lysate (10 $\mu \mathrm{g}$ protein) was used as a source of aminopeptidase $\mathrm{N}$ and incubated with $0.225 \mathrm{mg}(0.9 \mu \mathrm{mol})$ substrate in a reaction buffer in the presence and absence of inhibitors at $37^{\circ} \mathrm{C}$ for $2 \mathrm{~h}$. Aminopeptidase $\mathrm{N}$ activity was detected by absorbance at $405 \mathrm{~nm}$.

\section{Endothelial cell proliferation assay}

Essentially, the method described previously was used to determine the effect of endostatin on BCE cell proliferation (O’Reilly et al, 1997) by 3-(4,5-dimethylthiazol-2yl)-2,5-diphenyl2,4-tetrazolium bromide, MTT (Carmichael et al, 1987; Yoon et al, 1999).

\section{Endothelial cell migration assay}

The migration of endothelial cells was determined by using Boyden chambers (Neuro Probe, Gaithersburg, MD, USA) as previously described (Dhanabal et al, 1999).

\section{Tumour localisation}

LS174T cells were injected subcutaneously at right and left sides of the flanks of athymic nude mice. Tumour size reached about $500 \mathrm{~mm}^{3}$ on day 10 . Tumour-bearing mice were randomised into two groups. Endostatin or P125A-endostatin was injected at a dose of $20 \mathrm{mg} \mathrm{kg}^{-1}$ subcutaneously. Tumour tissues and representative normal tissues were surgically removed after $19 \mathrm{~h}$. This time point was chosen to minimise overwhelming serum levels from obscuring the tissue-bound endostatin. For comparison, serum samples were also collected from the mice. Tissues were snap frozen, and homogenised in RIPA buffer containing proteinase inhibitors (PBS, $1 \%$ NP40, $0.5 \%$ sodium deoxycholate, $0.1 \%$ SDS, $10 \mu \mathrm{g} \mathrm{ml}^{-1} \mathrm{PMSF}$ ), maintained at $4^{\circ} \mathrm{C}$ for $45 \mathrm{~min}$, and cleared by centrifugation. Human endostatin concentrations in serum and tissue lysates were measured using an enzyme-linked immunoassay (Cytimmune, College park, MD, USA) according to the manufacturer's instructions. Statistical significance was determined by Student's $t$-test.

\section{Matrigel plug assay}

Matrigel plug assay was used to determine inhibition of tumour cell-induced angiogenesis in vivo (Zhang et al, 2000). LS174T cell suspension was mixed with matrigel, and injected into nude mice subcutaneously. Mice were treated with native endostatin or P125A-endostatin at a dose of $20 \mathrm{mg} \mathrm{kg}^{-1}$ day $^{-1}$ subcutaneously at a distant site near the neck. Control mice were treated with an equal volume of sterile PBS at similar schedule. Treatment was started just after the matrigel implantation and continued for 1 week. At 1 day after the last treatment, the matrigel was removed. A part of the matrigel was used to prepare cryostat sections and another part of the samples was used for Real-time PCR analysis. Frozen sections $(10 \mu \mathrm{m})$ of matrigel were stained with $1: 50$ dilution of an anti-CD31 monoclonal antibody conjugated to phycoerythrin (MEC 13.3, BD PharMingen, San Diego, CA, USA) and analysed for vessel density (Wild et al, 2000). Serial frozen sections were used to localise VEGF by indirect immunoflourescence method using a polyclonal antiserum made against recombinant human $\mathrm{VEGF}_{165}$ (Olson et al, 1996). Another part of the matrigel samples were fixed in $10 \%$ neutral buffered formalin and processed for haematoxylin and eosin (H\&E) staining. 


\section{Quantitative real-time PCR analysis}

Total RNA was extracted from frozen matrigel samples using the RNeasy Mini kit (Qiagen, Valencia, CA, USA) according to the manufacturer's protocol. Reverse transcription was performed with the SuperScript II kit (Invitrogen) using $1 \mu \mathrm{g}$ of total RNA. Real-time PCR was carried out by using SYBR Green PCR Master Mix (Applied Biosystems, Foster City, CA, USA) in an ABI PRISM 7700 sequence detection system (Applied Biosystems) (TaqMan). Primer sequences described by Gerber et al (2000) were used (Table 1) to amplify proangiogenic factors related messages from the human tumour cells and relevant target receptors on endothelial cells of mouse origin. Following conditions were used for PCR: $50^{\circ} \mathrm{C}$ for $2 \mathrm{~min}, 95^{\circ} \mathrm{C}$ for $10 \mathrm{~min}$, and 40 cycles at $95^{\circ} \mathrm{C}$ for $0.15 \mathrm{~min}, 60^{\circ} \mathrm{C}$ for $1 \mathrm{~min}$. Negative controls included omission of the template. SYBR Green dye intercalation into the minor groove of double-stranded DNA reaches an emission maximum at $530 \mathrm{~nm}$. Relative RNA equivalents for each sample were calculated by either comparing to human or mouse GAPDH levels. Five to six samples per group were run in duplicate. Statistical analysis was performed by Student's $t$-test.

\section{Preparation of alginate beads encapsulated endostatins and tumour growth inhibition studies}

Alginic acid extracted from Macrocystis pyrifera was purchased from Sigma Chemicals, St. Louis, MO. A measure of $4 \%(\mathrm{w} / \mathrm{v})$ of alginic acid in water was sterilised by autoclaving. Endostatin preparations or PBS (control) made in $1.5 \%$ alginic acid were dropped gently into $0.1 \mathrm{M} \mathrm{CaCl}_{2}$ solution using a fine needle under aseptic conditions. Beads were kept at $4{ }^{\circ} \mathrm{C}$ overnight and were washed with sterile water before the subcutaneous implantation into tumour-bearing mice. Entrapment efficiency was calculated by determining the amount of protein remaining outside the beads from the total protein using the $\mathrm{BCA}$ protein assay kit (Pierce, Rockford, IL, USA). Logarithmically growing LS174T cells were harvested by trypsinisation and suspended in serum-free medium at a density of $1 \times 10^{7}$ cells ml $^{-1}$. A measure of $100 \mu \mathrm{l}$ of the single-cell suspension was then subcutaneously injected into the flanks of female athymic mice (6-8 weeks old). When the tumours became visible (3 days after inoculation), mice were randomised into groups and treated with endostatin-encapsulated alginate beads (five animals per group). Endostatins were implanted at a distant site (about $2 \mathrm{~cm}$ away) at a dose of $\sim 20 \mathrm{mg} \mathrm{kg}^{-1}$ once a week. Tumour growth was monitored by periodic caliper measurements. Tumour volume was calculated by the following formula: tumour volume $\left(\mathrm{mm}^{3}\right)=\left(a \times b^{2}\right) / 2$, where ' $a$ ' = length in $\mathrm{mm}$, ' $b$ ' $=$ width in $\mathrm{mm}$. Statistical significance between control and treated groups was determined by Student's $t$-test.

\section{RESULTS}

\section{Preparation and structural analysis of P125A endostatin}

Native human endostatin and a mutant with a proline to alanine substitution at position 125 were cloned and expressed in $P$. pastoris. The $\mathrm{P} 125 \mathrm{~A}$ mutation did not change the binding of endostatin to heparin. Like native human endostatin, P125Aendostatin bound to a heparin-ceramic column and eluted at around $300 \mathrm{~mm} \mathrm{NaCl}$ concentration, indicating similar binding strength to heparin (data not included).

An NGR-sequence capable of targeting endothelial cells is located immediately following the P125A-mutation site. Conformational features surrounding the mutation site are shown in Figure 1A. Crystallographic data published by Ding et al (1998) show that P125 is located in a loop flanked by two $\beta$-sheets. In order to determine whether the mutant protein was folded properly, gross secondary structural analysis of the P125A mutant was compared to the native protein made in the same expression system. The CD spectra of native and P125A human endostatin showed identical profiles, indicating that the two proteins have similar gross secondary structures (Figure 1B).

\section{P125A mutation-enhanced endothelial cell binding}

The biological characteristics of P125A-endostatin were compared to those of the native protein in a number of assays. As a first step, the ability to bind endothelial cells was assessed using cellattachment assays. Gelatin (0.2\%)-coated wells were used as a control, with the number of cells (HUVEC) attached to gelatincoated wells taken as $100 \%$ to calculate relative binding. By this standard, $38.5 \%$ of HUVEC attached to endostatin-coated wells. Under similar conditions, a significantly higher number of HUVEC (71\%) bound to wells coated with P125A-endostatin (Figure 1C) $(P=0.005)$. The observed differences in cell attachment are not due to variation in coating efficiencies, which were determined by ELISA method.

\section{Inhibition of endothelial cell migration}

A possible consequence of increased binding is increased biological activity. Previously, we showed that P125A-endostatin inhibited endothelial cell proliferation more efficiently than native endostatin did (Calvo et al, 2002). Endothelial cell migration assay is a more sensitive parameter to assess the biological activity of endostatin. Therefore, bFGF-induced migration of endothelial cells was determined in the presence of native and P125A-endostatin. Similar to the proliferation assays, this mutant endostatin was more effective than native protein in inhibiting cell migration (Figure 1D). At all three concentrations tested, P125A-endostatin inhibited endothelial cell migration more efficiently than native endostatin.

Table I Primer sequences used for real-time PCR

\begin{tabular}{|c|c|c|}
\hline Probe name & Forward primer & Reverse primer \\
\hline Human VEGF & AATGACGAGGGCGTGGAGT & TTGATCCGCATAATCTGCATG \\
\hline Human bFGF & TGAATCACTAACTGACTGAAAATTGA & GAAGGGTCTCCCGCATACT \\
\hline Human Ang I & CCTTCCAGCAATAAGTGGTAGTT & CAAACGGCTCCAGATTCA \\
\hline Human IL-8 & TITAGCATAGCTGGACATTAAAGAG & GCAAATATGCTTAGGCTTTAACC \\
\hline Human GAPDH & CCACCCATGGCAAATTCCATGGCA & TCTACACGGCAGGTCAGGTCCACC \\
\hline Mouse flt-I & GTCGGCTGCAGTGTGTAAGT & TGCTGTTCTCATCCGTTTCT \\
\hline Mouse flk-I & TGTCAAGTGGCGGTAAAGG & CACAAAGCTAAAATACTGAGGACTTG \\
\hline Mouse tie-2 & CGGCCAGGTACATAGGAGGAA & СССССАСТТСТGAGСТTСAC \\
\hline Mouse endoglin & GCAGGCAAGAACTCAGACAT & AGCTCCСTCAGCTTCTGTTT \\
\hline Mouse GAPDH & ATGTTCCAGTATGACTCCACTCACG & GAAGACACCAGTAGACTCCACGACA \\
\hline
\end{tabular}


A

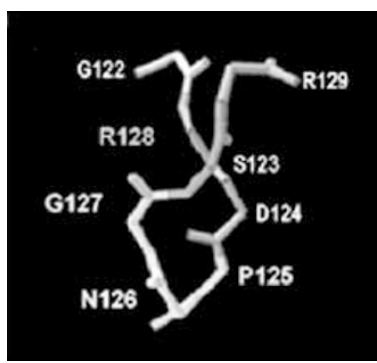

B

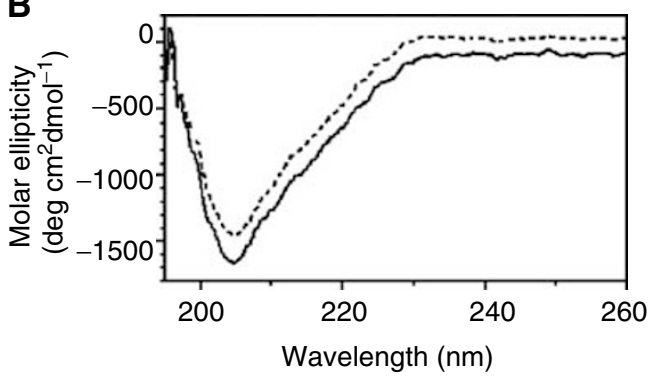

C

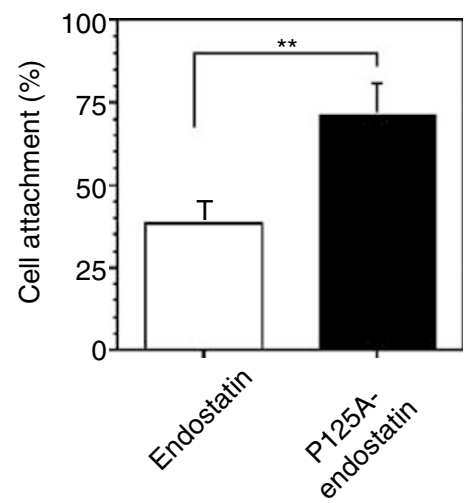

D

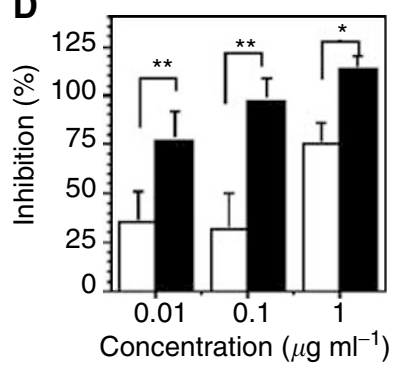

E

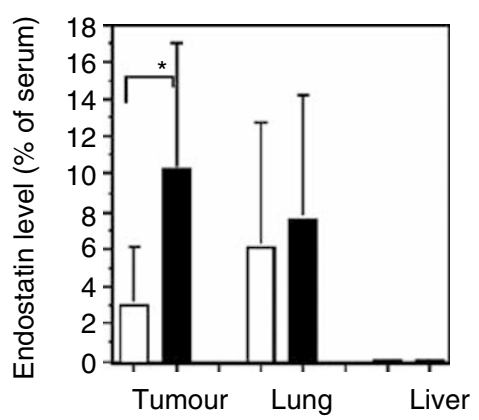

Figure I Characterisation of PI25A-endostatin-increased binding and biological activity. (A) Structural details surrounding the mutation site are shown. Swiss PDB Viewer programme was used to generate the figure based on the structural information published by Ding et al (I998). PI25 is followed by NI26, GI27, and RI28. (B) Circular dichroism spectroscopy of endostatin (---) and PI25A-endostatin (-). (C) Cell attachment assay. Single-cell suspension of HUVEC, prelabelled with 5(6)-CFDA, was added into triplicate wells coated with either endostatin or PI25A-endostatin at a concentration of I nmol well ${ }^{-1}$. Wells coated with $0.2 \%$ gelatin were used as maximum attachment (I00\%). Bound cells were quantified by a fluorescence plate reader. Values represent mean of two independent experiments. Data are expressed as a mean (columns) \pm s.d. (bars). Statistical significance was determined by Student's t-test. $* *$ P $<0.01$. (D) Effect of endostatin (open bars) and PI25A-endostatin (closed bars) on endothelial cell (HUVEC) migration. Basic FGF $\left(25 \mathrm{ng} \mathrm{ml}^{-1}\right.$ ) was used to induce migration of endothelial cells. Data are expressed as a mean (columns) \pm s.e. (bars). Statistical significance was determined using Student's t-test. $* P<0.05$, ** $P<0.0$ I. (E) Tumour Localisation. Human colon carcinoma cells (LSI 74T) were injected s.c. into female athymic nude mice. When the tumour size was around $500 \mathrm{~mm}^{3}$ ( 10 days after inoculation), Endostatin (open bars) or PI25A-endostatin (closed bars) was injected at a dose of $20 \mathrm{mg} \mathrm{kg}^{-1}$ subcutaneously. Endostatin levels were determined by ELISA. Endostatin levels are expressed as a percent of serum levels.

\section{Tumour localisation is improved by P125A-mutation}

To assess whether the improved endothelial cell binding in vitro can translate into enhanced tumour homing in vivo, tumour localisation studies were performed. Endostatin and P125Aendostatin were injected subcutaneously into human colon cancer-bearing athymic mice. Tumour, lung, liver and serum samples were collected. Relative levels of endostatin in the tissues are shown in Figure 1E. Native endostatin accumulated in the tumour tissues at a level of $3.0 \%$ when compared to serum levels. P125A-endostatin, on the other hand, was found at a more than three-fold higher concentration in the tumour tissue $(10.22 \%$ compared to serum levels). This difference was statistically significant $(P=0.03)$. While the liver showed negligible amounts of endostatins, lung tissues had significant accumulation of both native and mutant endostatin. However, lung tissues did not show any statistical difference between native and P125A-endostatin accumulation.

\section{Effect of endostatin and P125A-endostatin on aminopeptidase $\mathrm{N}$ activity}

As the mutation site is immediately followed by NGR motif, we next tested whether the mutant endostatin has aminopeptidase $\mathrm{N}$ inhibitory activity. Cellular extracts of aminopeptidase $\mathrm{N}$ enzyme were prepared from HUVEC. These cells express 8-10 times higher levels of aminopeptidase $\mathrm{N}$ compared to cancer cells such as 
A

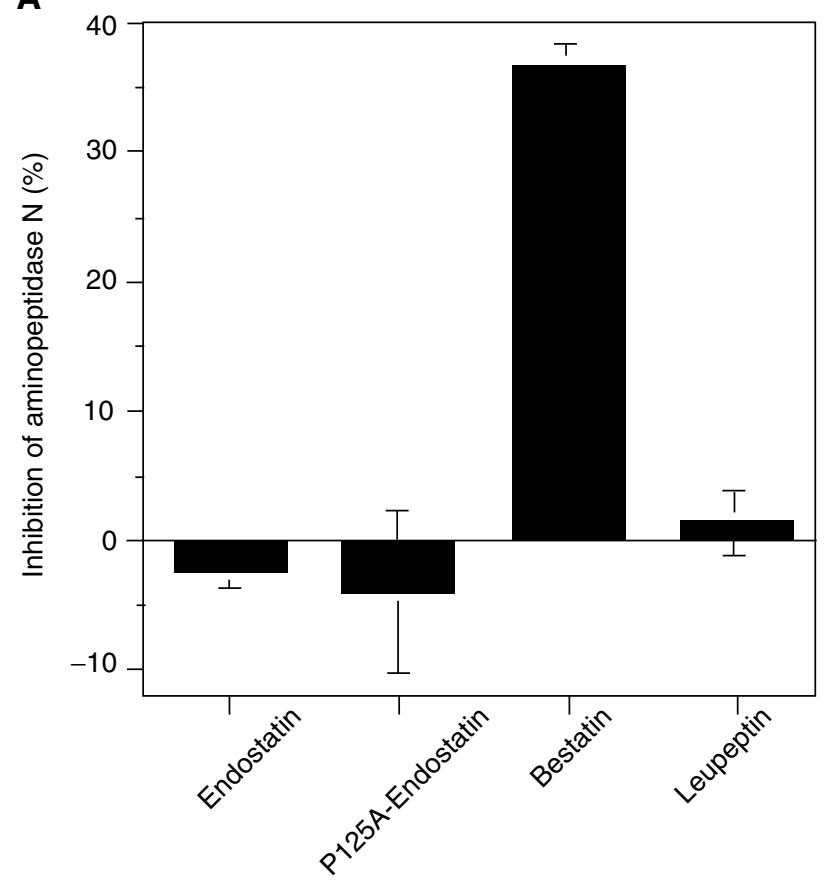

B

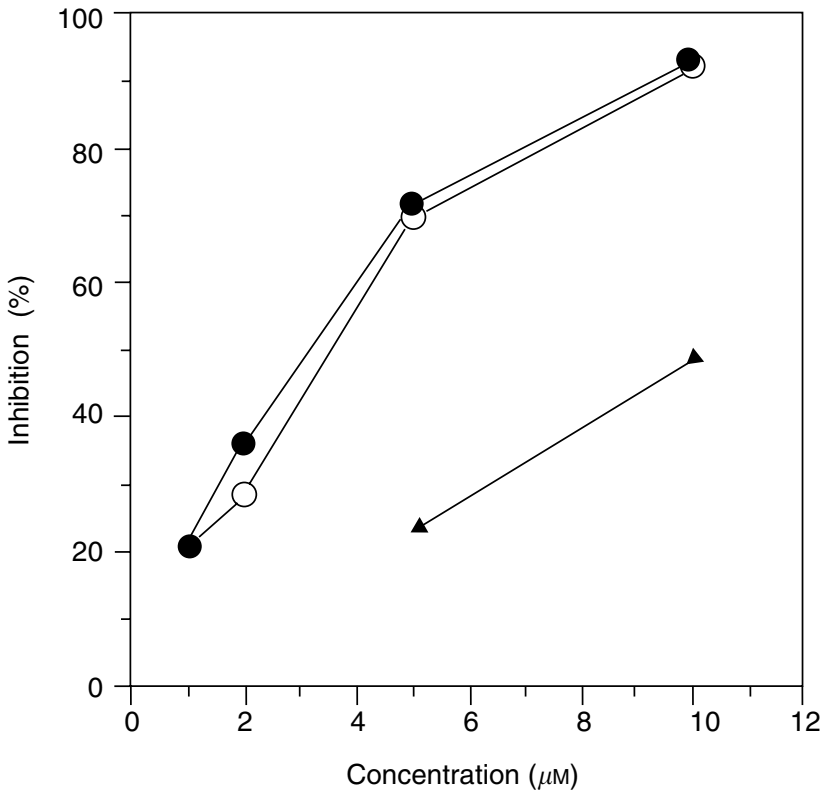

Figure 2 Effect of endostatin and synthetic peptides on aminopeptidase $\mathrm{N}$ activity. (A) Aminopeptidase $\mathrm{N}$ was extracted from HUVEC cultures. Bestatin was used as a positive control, and leupeptin treatment served as a negative control. Values represent mean of two independent experiments. (B) Two polypeptides containing 14 amino-acid residues (SI|8-TI3I) spanning the mutation site PI 25 were synthesised. One of the peptides had the native sequence and the other contained $\mathrm{P}$ to $\mathrm{A}$ substitution. Both peptides included the NGR motif. - SRI peptide (PI25A); O, SR2 peptide (native sequence); $\boldsymbol{\Delta}$, bestatin.

B16F10 (mouse melanoma), U937 (human monocytic leukaemia cell line), MA148 (human ovarian cancer cell line) and LS174T (human colon carcinoma cell line). Confluent HUVEC lysate showed about three times higher activity than proliferating HUVEC lysate (data not shown).
The data in Figure 2A show the effect of endostatin and its mutant on aminopeptidase $\mathrm{N}$ activity. As a positive control, the same concentration of bestatin, a known inhibitor of aminopeptidase $\mathrm{N}$, was included. Bestatin inhibited $35 \%$ of the enzymatic activity under the experimental conditions used. Leupeptin, a negative control, did not inhibit the enzyme. Interestingly, neither the native nor the P125A mutant showed any inhibition of aminopeptidase $\mathrm{N}$ activity even at $5 \mu \mathrm{m}$ concentration.

In a separate experiment, we tested whether synthetic peptides consisting of the amino acid sequence flanking the normal or mutated position 125 (S118-T131) could inhibit aminopeptidase N (Figure 2B). Interestingly, both peptides (native and mutant) inhibited aminopeptidase $\mathrm{N}$ activity more effectively than bestatin. At a concentration of $5 \mu \mathrm{M}$, the mutant and native peptide inhibited aminopeptidase $\mathrm{N}$ by 71.2 and $69.2 \%$, respectively. These studies suggest that the NGR motif in intact endostatin molecules constructs may not be accessible to interact with aminopeptidase N.

To confirm our findings, we characterised the interaction between endostatins and aminopeptidase $\mathrm{N}$ in an immunoabsorption assay using antibodies to human aminopeptidase $\mathrm{N}$ enzyme. Both synthetic peptides (A125 and P125) corresponding to the region S118-T131 were capable of binding to aminopeptidase $\mathrm{N}$, to similar levels. However, intact proteins (native and P125Aendostatin) did not show any detectable binding to aminopeptidase $\mathrm{N}$ (data not included). These results further confirm that the NGR motif in endostatin is not accessible for binding to aminopeptidase $\mathrm{N}$.

\section{Antiangiogenic activity of P125A-endostatin}

Next, we determined the ability of endostatin and P125Aendostatin to inhibit human colon cancer cell-induced angiogenesis in vivo using matrigel plug assays. Both endostatin and P125Aendostatin inhibited angiogenesis stimulated by LS174T colon carcinoma cells (Figure 3). Histological investigation of matrigels from control and treated (native or mutant endostatin) animals showed higher tumour cell density interspersed with welldeveloped blood vessels in control matrigels when compared to endostatin-treated groups. Endostatin-treated groups showed some of the tumour cells organised into islands. (Figure 3B, C, $\mathrm{E}$, and $\mathrm{F}$ ) when compared to control group treated with PBS (Figure 3A and D). Anti-CD31 staining of frozen sections showed quantitative difference between control and treated groups (Figure 4).

The overall indicators of angiogenesis, such as microvessel density (MVD), number of blood vessel ends (Ends), nodes (branch points), and length, showed that both endostatin and P125A-endostatin treatment significantly inhibited angiogenesis in vivo (Figure $3 \mathrm{H}$, I and Figure 4). Furthermore, endostatin treatment seemed to alter angiogenic growth factor expression in the tumour cell microenvironment. Cryostat sections of matrigels showed reduced amounts of VEGF in immunofluorescence studies using a polyclonal antibody made against human VEGF $_{165}$ (Figure $3 \mathrm{~K}$ and $\mathrm{L}$ ). Reduced VEGF levels may be a reflection of reduced number of tumour cells in the matrigel following endostatin treatment or due to an indirect effect of endostatin-mediated changes in the microenvironment.

\section{Downregulation of angiogenic factors and receptors by native and P125A-endostatin}

Previously, we showed that the mammary gland of P125Aendostatin-treated C3(1)/SV40 transgenic mice exhibited decreased mRNA levels of VEGF, angiopoietin-2, flk-1, flt-1, tie-1 and cadherin-5 when compared to PBS-treated control. In the present study, a different model system was used to determine selective changes in tumour-induced neovascularisation. Matrigel 

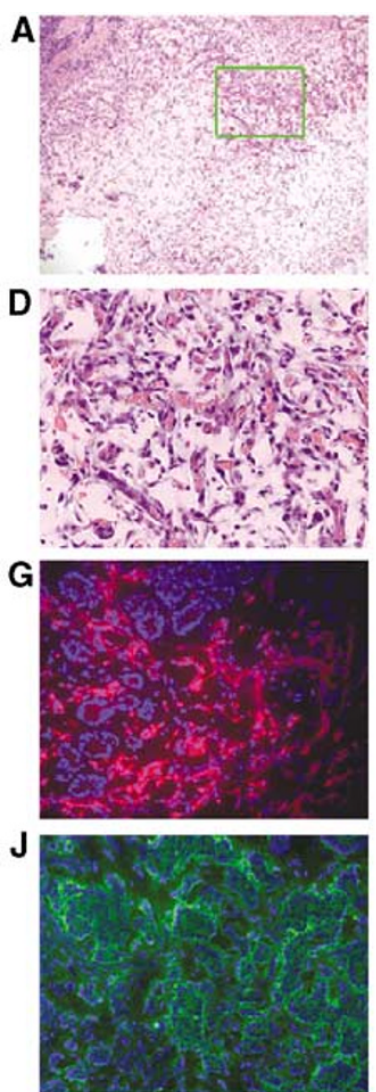

B

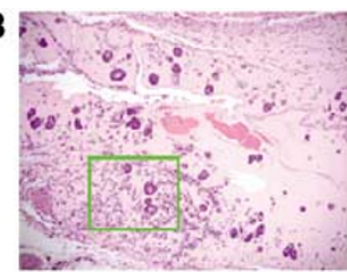

$E$
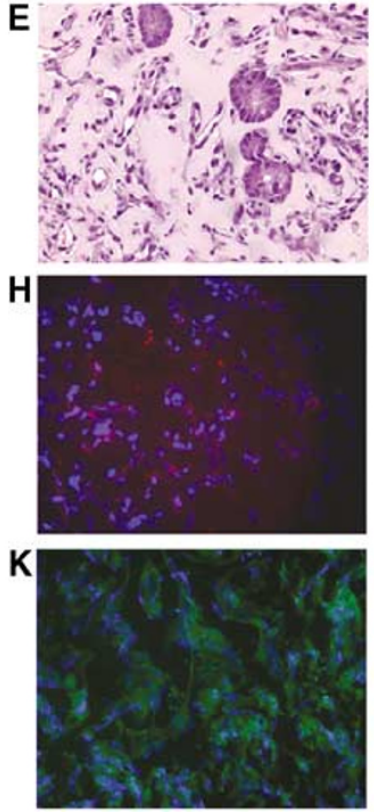

C
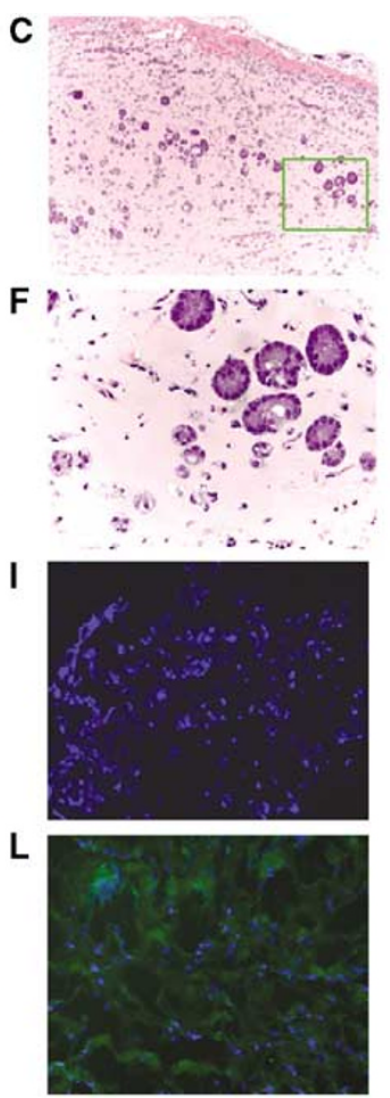

Figure 3 Histological analysis of matrigel plugs. Matrigel plugs containing LSI74 human colon cancer cell line were used to determine the effect of endostatin and PI25A-endostatin on angiogenesis. $((\mathbf{A})-(\mathbf{F}))$ Show H\&E staining; $((\mathbf{A})-(\mathbf{C})) \times 100$ magnification, $((\mathbf{D})-(\mathbf{F})) \times 400$ magnification, Green squares in $((\mathbf{A})-(\mathbf{C}))$ indicate the area of the images in $\times 400$ magnification of $(\mathbf{( D )}-(\mathbf{F}))$. $((\mathbf{G})-(\mathbf{I}))$ Show vessel staining with anti-CD3I antibody $($ red $)$ and nuclei staining with DAPI (blue) $\times 200$ magnification; $(\mathbf{J})-(\mathbf{L}))$ VEGF expression detected by indirect immunofluorescence using FITC-conjugated antibodies (green) with DAPI (blue). ((A), (D), (G), (J)) control; $((\mathbf{B}),(\mathbf{E}),(\mathbf{H}),(\mathbf{K}))$ native endostatin-treated matrigel sections; $((\mathbf{C}),(\mathbf{F}),(\mathbf{I}),(\mathbf{L}))$ P I25Aendostatin-treated matrigel sections.

plugs do not contain any other host cells or vasculature at the beginning of the experiment. Therefore, this model system is good to assess changes in tumour cell microenvironment following antiangiogenic therapy. To determine whether endostatin treatment altered RNA levels of proangiogenic factors from tumour and host receptors in newly formed blood vessels, real-time PCR was performed using total RNA isolated from the matrigel samples. Proangiogenic factors were detected by human gene-specific primers, and receptors were detected by mouse gene-specific primers (Table 1).

Results shown in Figure 5 demonstrate that mRNA levels of major proangiogenic growth factors (tumour cell derived) and receptors expressed on host endothelial cells were downregulated by endostatin or P125A-endostatin treatment. Moreover, VEGF and Ang1 expression were significantly decreased by P125Aendostatin when compared to native endostatin. Angiopoietin 2 transcript was not detected in any of the samples analysed. Basic FGF-related transcript levels were equally decreased by both the native and mutant endostatin.

Target receptors for the tumour-derived angiogenic factors are located on the host vascular endothelial cells. Therefore, mousespecific primers were used to study the levels of receptor molecules for VEGF and Ang1. These studies showed that both native and P125A-endostatin decreased mRNA levels of flt-1, flk-1, tie-2 and endoglin, a coreceptor for TGF-beta. Although native endostatin showed a slightly better effect when compared to the mutant protein in decreasing flk-1 and flt-1, the differences were not statistically significant.

\section{Inhibition of tumour growth by endostatin and P125A- endostatin}

Microencapsulated endostatin is more effective than bolus administration. In our previous studies, we showed that alginate beads of P125A-endostatin was more effective in inhibiting MA148 ovarian cancer growth when compared to the native protein given under similar condition (Calvo et al, 2002). These results were confirmed in a human colon cancer model system (Figure 6). LS174T colon cancer cell line, which was used in the previous matrigel plug assay, grows aggressively in athymic mice and visible tumours can be seen as early as 3 days after subcutaneous injection. Endostatins encapsulated in alginate beads were given twice on days 3 and 10 at a dose of $20 \mathrm{mg} \mathrm{kg}^{-1}$. Although native endostatin exhibited only a marginal inhibition of LS174T tumour growth, P125A-endostatin treatment resulted in significantly enhanced antitumour activity. At the end of the experiment, native endostatin showed $30 \%$ inhibition of tumour growth, but P125A-endostatin decreased tumour size by $75 \%$ when compared to PBS-treated control animals. These studies confirm that P125Aendostatin inhibits tumour growth more effectively than the native protein. 
A

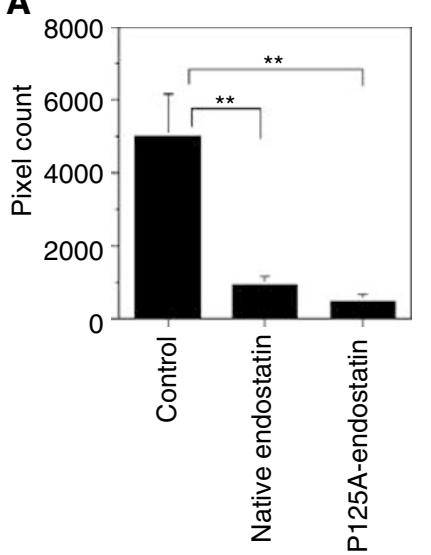

C

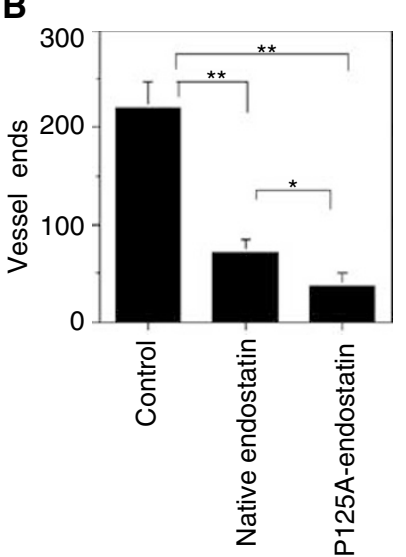

D

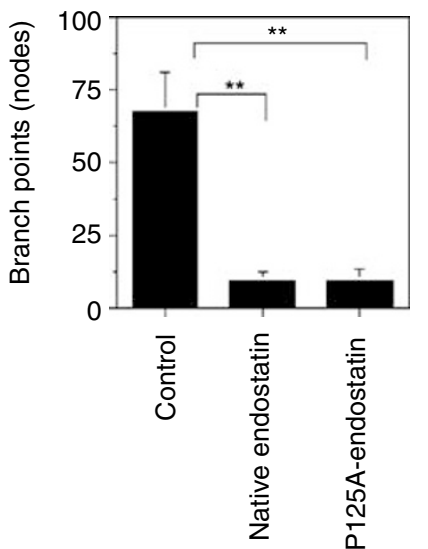

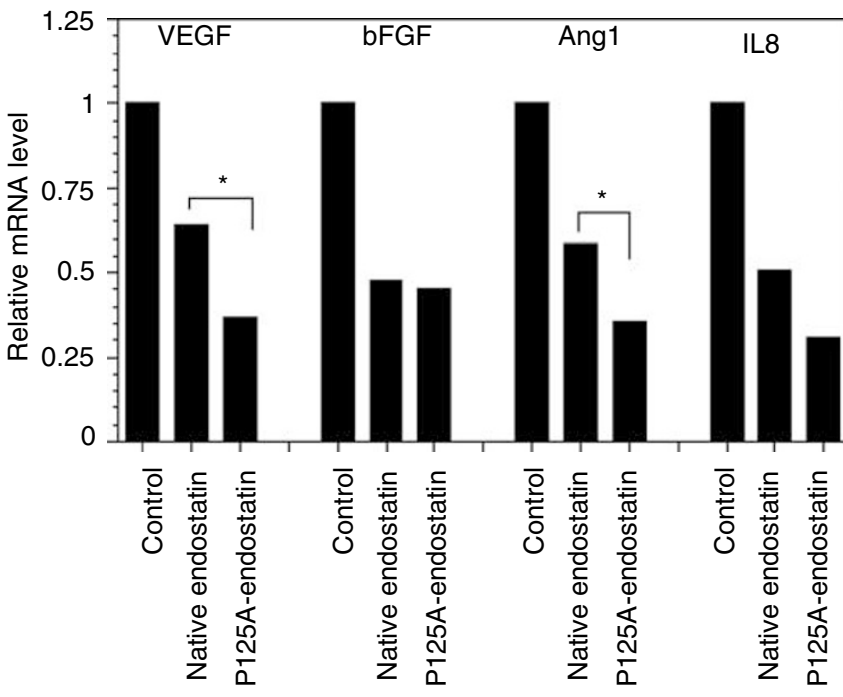

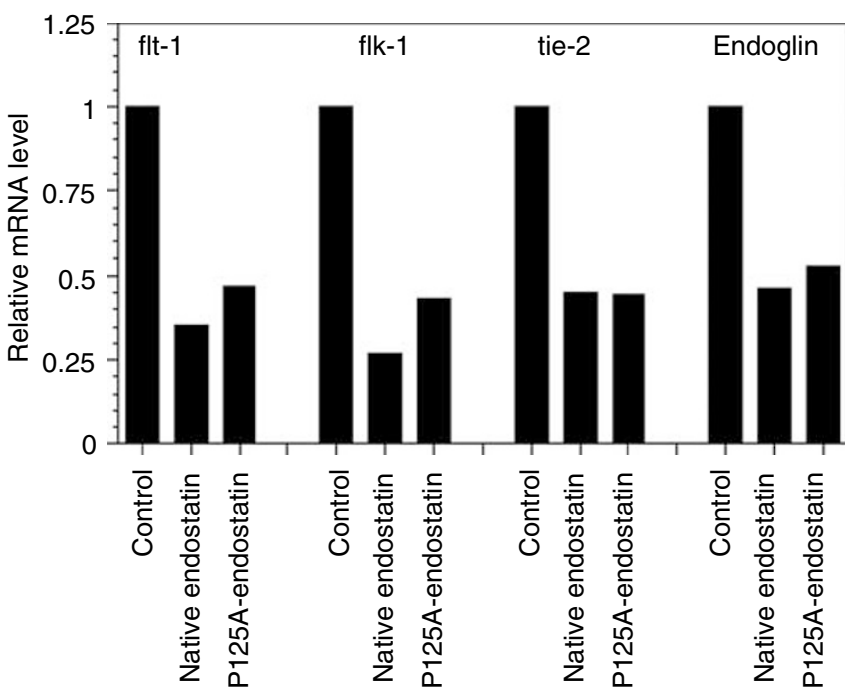

Figure $\mathbf{5}$ Downregulation of proangiogenic growth factors and receptors by endostatin treatment. Real-time PCR data were normalised by mRNA level to GAPDH. Data show relative mRNA levels. Messenger RNA of human proangiogenic factors (VEGF, bFGF, AngI and IL8) and mouse receptors (flt-I, flk-I, tie-2 and Endoglin) in Matrigel plugs were downregulated by endostatin and PI25A-endostatin treatment.

moderate inhibition was observed (Dhanabal et al, 1999; Yokoyama et al, 2000). Understanding the basis for these discrepancies may help in the successful clinical development of endostatins. Alternatively, structure/function studies can be used to generate more potent angiogenic inhibitors. Proline 125 is located in a $\beta$-hairpin loop between the $\beta$ sheets $\mathrm{K}$ and $\mathrm{L}$ of human endostatin. An endothelial cell homing motif, NGR, is located immediately following this mutation site in human endostatin. In mouse endostatin, however, the SGR sequence is seen in place of NGR. The NGR motif was originally identified while mining for sequences capable of homing to tumour vasculature using Phage display libraries (Pasqualini et al, 2000). In spite of the nonconservative substitution of a proline to alanine, the mutant protein was expressed in soluble form and was biologically active. The CD spectrum showed that P125A-mutation did not cause major structural change. Asn-Gly-Arg-containing peptides are known to inhibit endothelial cell membrane-associated aminopeptidase $\mathrm{N}$ activity. However, neither the native nor the mutant and expressed (Dhanabal et al, 1999). In a number of model systems, endostatin treatment either inhibited or regressed experimental tumours (O'Reilly et al, 1997). In some studies, only 


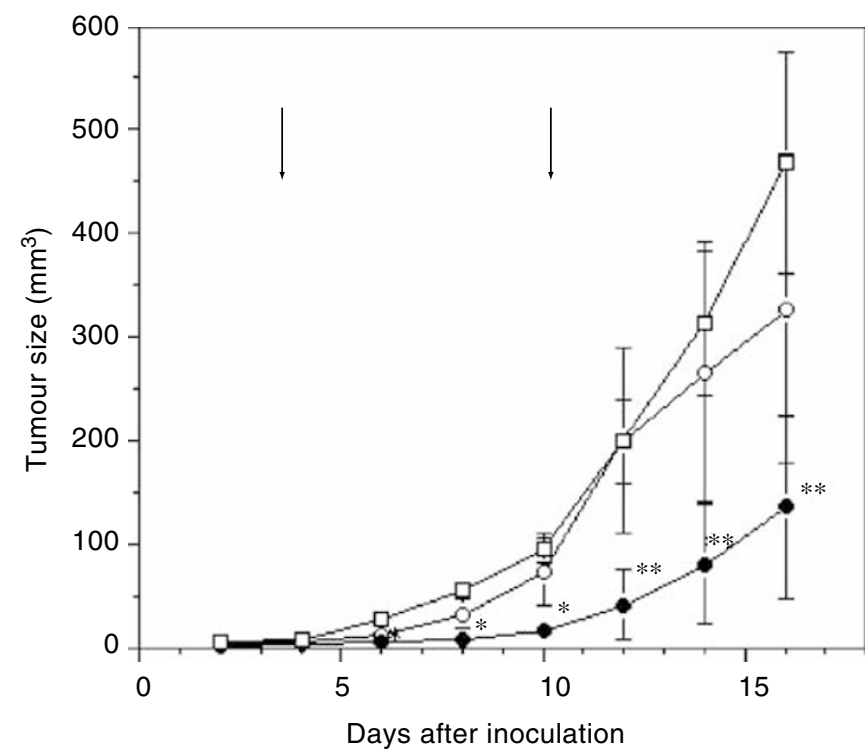

Figure 6 Improved inhibition of tumour growth by PI25A-Endostatin. Human colon carcinoma cell line, LSI74T was injected S.c. into female athymic mice. After tumours reached a palpable size, mice were treated with endostatin and PI25A-endostatin encapsulated in alginate beads (s.c.) at a dose of $20 \mathrm{mg} \mathrm{kg}^{-1}$ week $^{-1}$. Endostatins were administered two times I week apart to colon cancer-bearing mice. Arrows denote time points at which microencapsulated endostatins were administered. Two endostatin treatments were given I week apart: $\square$, alginate bead control (PBS); $\bigcirc$, endostatin; - PI25A-endostatin. The mean tumour volume of control and treated groups are shown. Statistical significance was determined using Student's t-test. $* P<0.05$, $* * P<0.01$. The error bars indicate s.e.

protein showed any detectable inhibition of aminopeptidase $\mathrm{N}$. Although synthetic peptides corresponding to this region showed potent inhibition of aminopeptidase $\mathrm{N}$, these studies suggest that the internal NGR sequence in endostatin is constrained and not accessible to bind aminopeptidase N. Furthermore, inhibition of this enzyme may not be directly relevant to the biological activity of endostatin since mouse and human endostatin have different sequences (SGR and NGR, respectively).

Endostatin binds to two distinct classes of proteins on the endothelial cell surface. $\alpha_{5} \beta_{1} / \alpha_{v} \beta_{3}$ integrins and heparin sulphateglycosaminoglycan component of the glypican have been reported to be direct targets for endostatin. The domains of endostatin, which are involved in binding the target molecules on endothelial cell surface, have not been completely characterised. The heparinbinding domain of endostatin is composed of a number of positively charged arginine residues (Yamaguchi et al, 1999). There are 15 arginine residues in mouse endostatin of which 14 are conserved in human endostatin. In fact, synthetic peptides emcompassing these arginine regions showed antiangiogenic properties (Kasai et al, 2002). Other reports showed that mutagenesis of some of the arginine residues either individually or in pairs changed their affinity to heparin. These changes, however, did not affect the biological activity significantly (Sasaki et al, 1999; Yamaguchi et al, 1999). Our studies show that the P125A-mutation does not affect heparin binding. This conclusion is based on the $\mathrm{NaCl}$ concentration required to elute native and mutant protein from heparin affinity column.

However, cell attachment assays showed that P125A-endostatin bound more avidly than native endostatin. Enhanced binding to endothelial cells led to improved biological activity, indicated by the results of endothelial cell proliferation and migration assays. In both the assays, the P125A-mutation increased bioactivity of endostatin. Enhanced binding to endothelial cells also led to improved tumour localisation of endostatin. The homing specificity of endostatin to tumours compared to lung or liver tissue was also improved by $\mathrm{P} 125 \mathrm{~A}$-mutation. It is interesting that only tumour accumulation was changed by $\mathrm{P} 125 \mathrm{~A}$ mutation. These results suggest that the target molecule for $\mathrm{P} 125 \mathrm{~A}$ is perhaps upregulated in tumour vasculature, thereby facilitating higher binding.

Higher tumour homing also coincided with better in vivo activity in matrigel plug assay. Treated matrigels showed tumour cells forming glandular structures. Recently, Hajitou et al also reported a similar finding. Endostatin or angiostatin delivered by adenoviral vectors inhibited local invasion and tumour vascularisation of transplanted murine malignant keratinocytes (Hajitou et al, 2002).

Real-time PCR data showed that mRNA levels of proangiogenic factors and receptors were downregulated by endostatin treatment, with VEGF and Ang1 downregulated more by P125A-endostatin when compared to native endostatin. Histochemical analysis also showed that VEGF protein levels were decreased in endostatin or P125A-endostatin-treated tumour tissues. Our results are in agreement with those of Calvo et al (2002) who showed, in the C3(1)/SV40 transgenic mouse model, that P125A-endostatin treatment suppressed mRNA and protein levels of VEGF, Female C3(1)/SV40 mice treated with P125A-endostatin for a 3-week period showed significant delay in tumour development, reduced tumour burden and increased survival (Calvo et al, 2002). Hajitou et al (2002) also showed 3-10-fold downregulation of VEGF mRNA expression in endostatin-treated aortic ring. These results indicate that endostatin affects proangiogenic factor expression in the tumour microenvironment.

Slow release of endostatin by alginate encapsulation was used to determine antitumour efficacy. Unlike the bolus injection protocol, alginate-entrapped endostatin was given once a week. This method reduced the cumulative dose to be given to each mouse by sevenfold. Kisker et al (2001) also showed that continuous administration using a miniosmotic pump increased the potency of endostatin therapy. Present studies clearly demonstrate that P125A-endostatin inhibits colon carcinoma growth more effectively when compared to the native endostatin.

In summary, these studies show that human endostatin can be genetically modified to improve its ability to bind and inhibit endothelial cells. Higher binding also coincided with changes in potency in inhibiting cell proliferation and migration, and in homing to tumours. Such differences in tumour-homing properties can contribute to improved antitumour activity of mutant endostatin.

The mechanism of enhanced binding to endothelial cells of P125A-endostatin still not entirely clear. It is likely that binding to glypican (supported by heparin-binding data) is not altered by P125A mutation. However, the P125A mutation may expose cryptic determinants in endostatin, which can in turn bind to novel target molecules on endothelial cells. Such an interaction may enhance binding of P125A-endostatin to endothelial cells. We initially hypothesised that aminopeptidase $\mathrm{N}$ could be a potential target for P125A-endostatin. However, our current studies clearly demonstrated that P125A-endostatin did not bind to aminopeptidase N. Further work will be necessary to understand the molecular target and mechanism of enhanced binding of P125Aendostatin to endothelial cells.

\section{ACKNOWLEDGEMENTS}

This work was supported in part by a grant from the USMRMC (DAMD17-99-19564), Gynecologic Oncology Group and Minnesota 
Ovarian Cancer Alliance. We thank Dr Robin L Bliss, Comprehensive Cancer Center, for statistical analysis, and Ms Shaoying Li for technical assistance. Dr Thao Yang and Anna Maria Piras helped in the CD spectral analysis of proteins.

\section{REFERENCES}

Arap W, Pasqualini R, Ruoslahti E (1998) Cancer treatment by targeted drug delivery to tumor vasculature in a mouse model. Science 279: 377-380

Boehm T, Folkman J, Browder T, O’Reilly MS (1997) Antiangiogenic therapy of experimental cancer does not induce acquired drug resistance (see comments). Nature 390: 404-407

Calvo A, Yokoyama Y, Smith LE, Ali I, Shih SC, Feldman AL, Libutti SK, Ramakrishnan S, Green JE (2002) Inhibition of the mammary carcinoma angiogenic switch in C3(1)/SV40 transgenic mice by a mutated form of human endostatin. Int J Cancer 101: 224-234

Carmichael J, DeGraff WG, Gazdar AF, Minna JD, Mitchell JB (1987) Evaluation of a tetrazolium-based semiautomated colorimetric assay: assessment of chemosensitivity testing. Cancer Res 47: 936-942

Dhanabal M, Ramchandran R, Volk R, Stillman IE, Lombardo M, IruelaArispe ML, Simons M, Sukhatme VP (1999) Endostatin: yeast production, mutants, and antitumor effect in renal cell carcinoma. Cancer Res 59: $189-197$

Ding YH, Javaherian K, Lo KM, Chopra R, Boehm T, Lanciotti J, Harris BA, Li Y, Shapiro R, Hohenester E, Timpl R, Folkman J, Wiley DC (1998) Zinc-dependent dimers observed in crystals of human endostatin. Proc Natl Acad Sci USA 95: 10443-10448

Dixelius J, Larsson H, Sasaki T, Holmqvist K, Lu L, Engstrom A, Timpl R, Welsh M, Claesson-Welsh L (2000) Endostatin-induced tyrosine kinase signaling through the $\mathrm{Shb}$ adaptor protein regulates endothelial cell apoptosis. Blood 95: $3403-34011$

Gerber HP, Kowalski J, Sherman D, Eberhard DA, Ferrara N (2000) Complete inhibition of rhabdomyosarcoma xenograft growth and neovascularization requires blockade of both tumor and host vascular endothelial growth factor. Cancer Res 60: 6253-6258

Hajitou A, Grignet C, Devy L, Berndt S, Blacher S, Deroanne CF, Bajou K, Fong T, Chiang Y, Foidart JM, Noel A (2002) The antitumoral effect of endostatin and angiostatin is associated with a down-regulation of vascular endothelial growth factor expression in tumor cells. FASEB J 16: $1802-1804$

Hanai J, Karumanchi SA, Kale S, Tank J, Hu G, Chan B, Ramchandran R, Jha V, Sukhatme VP, Sokol S (2002) Endostatin is a potential inhibitor of Wnt signaling. J Cell Biol 158: 529-539

Kamphaus GD, Colorado PC, Panka DJ, Hopfer H, Ramchandran R, Torre A, Maeshima Y, Mier JW, Sukhatme VP, Kalluri R (2000) Canstatin, a novel matrix-derived inhibitor of angiogenesis and tumor growth. J Biol Chem 275: 1209-1215

Karumanchi SA, Jha V, Ramchandran R, Karihaloo A, Tsiokas L, Chan B, Dhanabal M, Hanai JI, Venkataraman G, Shriver Z, Keiser N, Kalluri R, Zeng $\mathrm{H}$, Mukhopadhyay $\mathrm{D}$, Chen RL, Lander AD, Hagihara K, Yamaguchi Y, Sasisekharan R, Cantley L, Sukhatme VP (2001) Cell surface glypicans are low-affinity endostatin receptors. Mol Cell 7: 811 822

Kasai S, Nagasawa H, Shimamura M, Uto Y, Hori H (2002) Design and synthesis of antiangiogenic/heparin-binding arginine dendrimer mimicking the surface of endostatin. Bioorg Med Chem Lett 12: 951 -954

Kim YM, Jang JW, Lee OH, Yeon J, Choi EY, Kim KW, Lee ST, Kwon YG (2000) Endostatin inhibits endothelial and tumor cellular invasion by blocking the activation and catalytic activity of matrix metalloproteinase. Cancer Res 60: 5410-5413

Kisker O, Becker CM, Prox D, Fannon M, D’Amato R, Flynn E, Fogler WE, Sim BK, Allred EN, Pirie-Shepherd SR, Folkman J (2001) Continuous administration of endostatin by intraperitoneally implanted osmotic pump improves the efficacy and potency of therapy in a mouse xenograft tumor model. Cancer Res 61: 7669-7674

Lin HC, Chang JH, Jain S, Gabison EE, Kure T, Kato T, Fukai N, Azar DT (2001) Matrilysin cleavage of corneal collagen type XVIII NC1 domain and generation of a $28-\mathrm{kDa}$ fragment. Invest Ophthalmol Vis Sci 42: $2517-2524$
Maeshima Y, Colorado PC, Kalluri R (2000) Two RGD-independent alpha vbeta 3 integrin binding sites on tumstatin regulate distinct anti-tumor properties. J Biol Chem 275: 23745-23750

O'Reilly MS, Boehm T, Shing Y, Fukai N, Vasios G, Lane WS, Flynn E, Birkhead JR, Olsen BR, Folkman J (1997) Endostatin: an endogenous inhibitor of angiogenesis and tumor growth. Cell 88: 277-285

Oh SP, Kamagata Y, Muragaki Y, Timmons S, Ooshima A, Olsen BR (1994) Isolation and sequencing of CDNAs for proteins with multiple domains of Gly-Xaa-Yaa repeats identify a distinct family of collagenous proteins. Proc Natl Acad Sci USA 91: 4229-4233

Olson TA, Mohanraj D, Ramakrishnan S (1996) In vivo neutralization of vascular endothelial growth factor (VEGF)/vascular permeability factor (VPF) inhibits ovarian carcinoma-associated ascites formation and tumor growth. Int J Oncol 8: 505-511

Pasqualini R, Koivunen E, Kain R, Lahdenranta J, Sakamoto M, Stryhn A, Ashmun RA, Shapiro LH, Arap W, Ruoslahti E (2000) Aminopeptidase N is a receptor for tumor-homing peptides and a target for inhibiting angiogenesis. Cancer Res 60: 722-727

Ramakrishnan S, Olson TA, Bautch VL, Mohanraj D (1996) Vascular endothelial growth factor-toxin conjugate specifically inhibits KDR/flk-1positive endothelial cell proliferation in vitro and angiogenesis in vivo. Cancer Res 56: $1324-1330$

Ramchandran R, Dhanabal M, Volk R, Waterman MJ, Segal M, Lu H, Knebelmann B, Sukhatme VP (1999) Antiangiogenic activity of resitin, NC10 domain of human collagen XV: comparison to endostatin. Biochem Biophys Res Commun 255: 735-739

Rehn M, Veikkola T, Kukk-Valdre E, Nakamura H, Ilmonen M, Lombardo C, Pihlajaniemi T, Alitalo K, Vuori K (2001) Interaction of endostatin with integrins implicated in angiogenesis. Proc Natl Acad Sci USA 98: 1024-1029

Sasaki T, Larsson H, Kreuger J, Salmivirta M, Claesson-Welsh L, Lindahl U, Hohenester E, Timpl R (1999) Structural basis and potential role of heparin/heparan sulfate binding to the angiogenesis inhibitor endostatin. EMBO J 18: $6240-6248$

Shichiri M, Hirata Y (2001) Antiangiogenesis signals by endostatin. FASEB J 15: $1044-1053$

Wen W, Moses MA, Wiederschain D, Arbiser JL, Folkman J (1999) The generation of endostatin is mediated by elastase. Cancer Res 59: 6052-6056

Wickstrom SA, Alitalo K, Keiski-Oja J (2002) Endostatin associates with integrin alpha5beta1 and caveolin-1, and activates Src via a tyrosyl phosphatase-dependent pathway in human endothelial cells. Cancer Res 62: $5580-5589$

Wild R, Ramakrishnan S, Sedgewick J, Griffioen AW (2000) Quantitative assessment of angiogenesis and tumor vessel architecture by computerassisted digital image analysis: effects of VEGF-toxin conjugate on tumor microvessel density. Microvasc Res 59: 368-376

Yamaguchi N, Anand-Apte B, Lee M, Sasaki T, Fukai N, Shapiro R, Que I, Lowik C, Timpl R, Olsen BR (1999) Endostatin inhibits VEGF-induced endothelial cell migration and tumor growth independently of zinc binding. EMBO J 18: $4414-4423$

Yokoyama Y, Dhanabal M, Griffioen AW, Sukhatme VP, Ramakrishnan S (2000) Synergy between angiostatin and endostatin: inhibition of ovarian cancer growth. Cancer Res 60: 2190-2196

Yokoyama Y, Ramakrishnan (2002) Substitution of a single amino acid residue in human endostatin potentiates inhibition of ovarian and colon cancer growth. Keystone Symposia.

Yoon SS, Eto H, Lin CM, Nakamura H, Pawlik TM, Song SU, Tanabe KK (1999) Mouse endostatin inhibits the formation of lung and liver metastases (in process citation). Cancer Res 59: 6251-6256

Zhang L, Yu D, Hu M, Xiong S, Lang A, Ellis LM, Pollock RE (2000) Wildtype p53 suppresses angiogenesis in human leiomyosarcoma and synovial sarcoma by transcriptional suppression of vascular endothelial growth factor expression. Cancer Res 60: 3655-3661 